\title{
Design of clinical cardioprotection trials using CMR: impact of myocardial salvage index and a narrow inclusion window on sample size
}

Henrik Engblom ${ }^{1 *}$, Einar Heiberg ${ }^{1}$, Svend Eggert Jensen², Jan Erik Nordrehaug ${ }^{3}$, Jean-Luc Dubois-Randé ${ }^{4}$, Sigrun Halvorsen ${ }^{5}$, Sasha Koul ${ }^{6}$, David Erlinge ${ }^{6}$, Dan Atar ${ }^{5}$, Marcus Carlsson ${ }^{1}$, Håkan Arheden $^{1}$

From 18th Annual SCMR Scientific Sessions

Nice, France. 4-7 February 2015

\section{Background}

Cardiac magnetic resonance imaging (CMR) can be used to determine both myocardial infarct (MI) size and myocardium at risk (MaR), enabling assessment of myocardial salvage index (MSI). MI size as assessed by hyperenhancement on late gadolinium enhancement (LGE) has been shown to decrease approximately $25 \%$ during the first week after infarction. The aim of this study was to determine to what extent assessment of MSI and a narrow inclusion window affect the number of patients needed to reach sufficient statistical power in a clinical CMR cardioprotection trial.

\section{Methods}

Control subjects $(\mathrm{n}=91)$ from the recent CHILL-MI ${ }^{1}$ and MITOCARE ${ }^{2}$ cardioprotection trials, examined by CMR 2-6 days after acute reperfusion therapy, were used to assess the difference in sample size required to reach sufficient statistical power when using MI size alone compared to MSI as outcome variable. In addition, 22 patients undergoing CMR at day 1 and 7 after acute reperfused infarction from a previous follow-up study ${ }^{3}$ were included to assess to what extent sample size is affected by the decrease in hyperenhancement seen during the first week after infarction. The variability of MI size by LGE, MaR by contrast-enhanced SSFP and MSI was used to simulate 100.000 clinical trials for different assumed treatment effects to determine the number of patients needed to reach sufficient statistical power.

\section{Results}

For an assumed effect of $25 \%$ reduction in MI size by a cardioprotection treatment, the number of patients needed to reach sufficient statistical power can be reduced by $48 \%$ (34 patients in each arm versus 65 ) if using MSI instead of MI size alone as outcome variable (Figure 1). If a fixed time point for the CMR examination
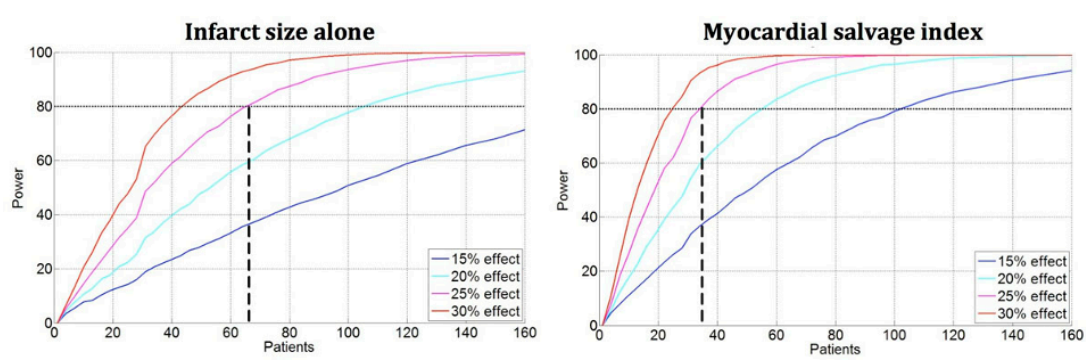

Figure 1 The number of patients needed in each arm to reach sufficient statistical power.

${ }^{1}$ Cardiac MR group Lund, Dept. of Clinical Physiology, Lund University, Lund,

Sweden

Full list of author information is available at the end of the article 

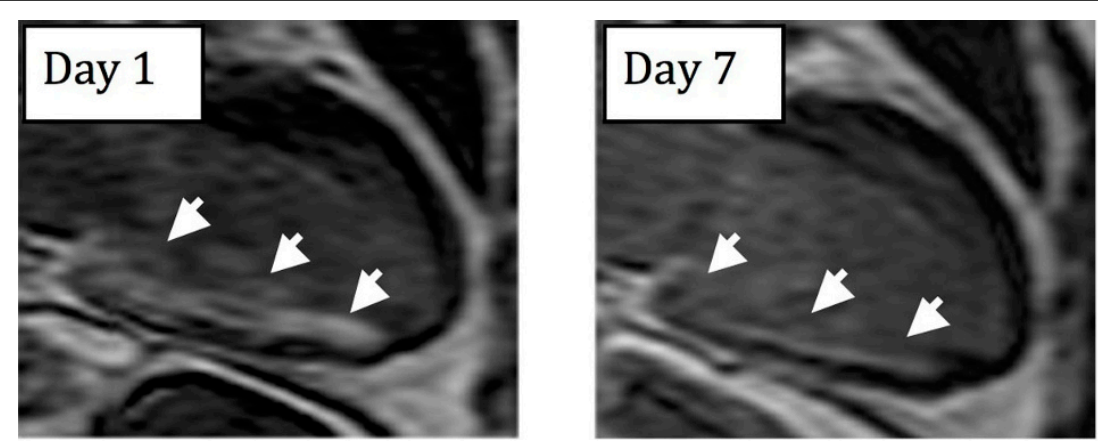

Figure 2 Change in hyperenhancement (arrows) day 1 and 7 after acute reperfusion therapy in a patient with inferior infarction.

is used instead of an inclusion window of 1-7 days after infarction, the number of patients needed to reach sufficient statistical power decreased by $31 \%$ for infarct size alone and 23\% for MSI. Figure 2 shows an example of the reduction of hyperenhancement between day 1 and 7 .

\section{Conclusions}

There is a significant reduction in sample size needed to reach sufficient statistical power in CMR cardioprotection trials when using MSI instead of MI size alone as outcome variable. In addition, sample size can be further reduced by narrowing the inclusion window during the first week after the acute event.

\section{Authors' details \\ ${ }^{1}$ Cardiac MR group Lund, Dept. of Clinical Physiology, Lund University, Lund, Sweden. ${ }^{2}$ Department of Cardiology, Aalborg University Hospital, Aalborg, Denmark. ${ }^{3}$ Department of Cardiology, Haukeland University Hospital, Bergen, Norway. ${ }^{4}$ Department of Cardiology, Henri Mondor Hospital, Creteil, France. ${ }^{5}$ Department of Cardiology B, Oslo University Hospital Ullevål, and Faculty of Medicine, University of Oslo, Oslo, Norway. ${ }^{6}$ Department of Cardiology, Lund University Hospital and Lund University, Lund, Sweden.}

Published: 3 February 2015

\section{References}

1. Erlinge, et al: JACC 2014, 63:1857-65.

2. Atar, et al: EHJ 2014, Epub ahead.

3. Engblom, et al: Circ Cl 2009, 2:47-55.

\section{doi:10.1186/1532-429X-17-S1-P90}

Cite this article as: Engblom et al:: Design of clinical cardioprotection trials using CMR: impact of myocardial salvage index and a narrow inclusion window on sample size. Journal of Cardiovascular Magnetic Resonance 2015 17(Suppl 1):P90.

\section{Submit your next manuscript to BioMed Central} and take full advantage of:

- Convenient online submission

- Thorough peer review

- No space constraints or color figure charges

- Immediate publication on acceptance

- Inclusion in PubMed, CAS, Scopus and Google Scholar

- Research which is freely available for redistribution 